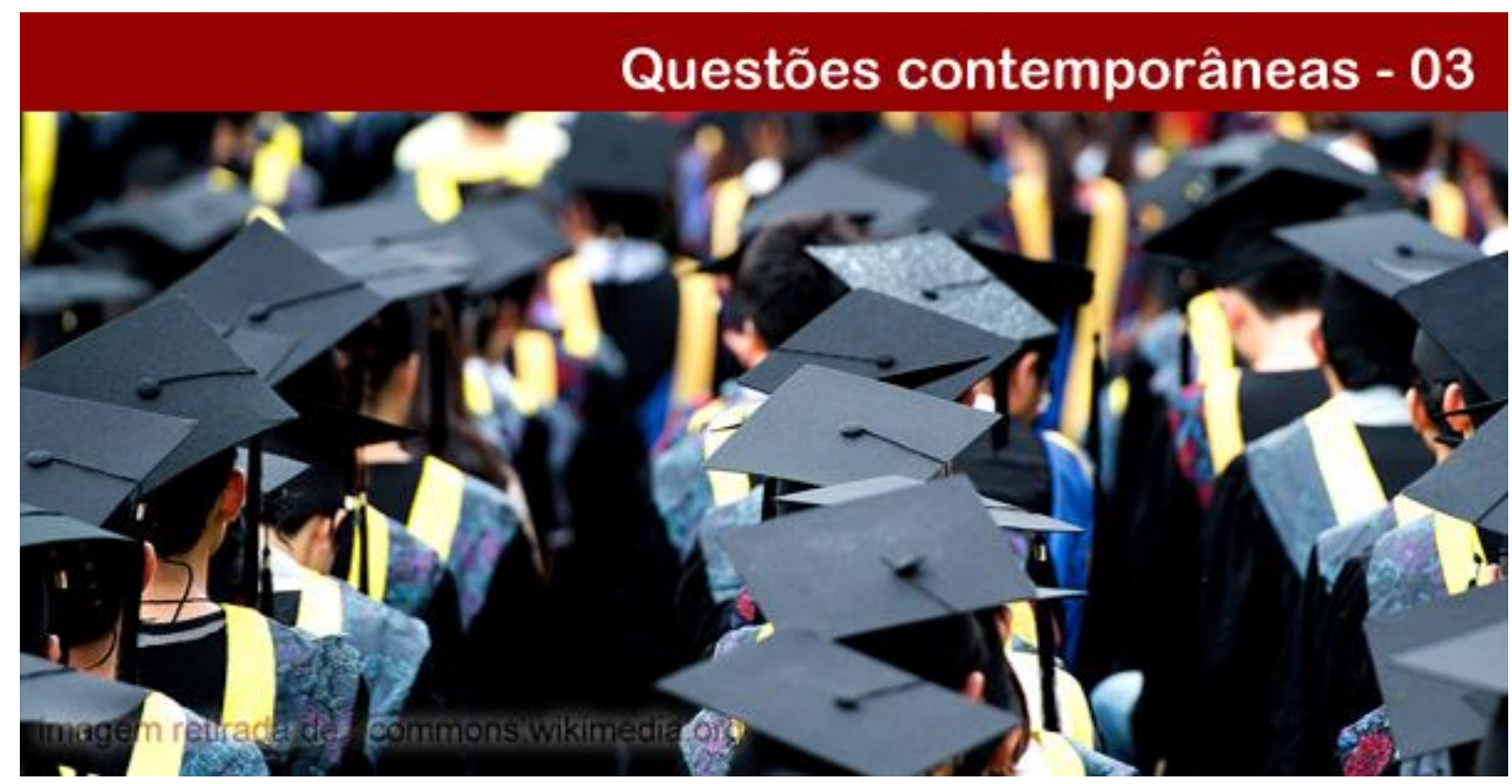

\title{
HABILIDADES SOCIAIS E AUTOEFICÁCIA EM UNIVERSITÁRIOS
}

Joyce Mendes da Cruz Guimarães

Graduanda de psicologia do Centro universitário Augusto Motta.E-mail: cruz.joy@gmail.com.

Renata dos Santos Vieira

Graduanda de psicologia do Centro universitário Augusto Motta. E-mail: pra.renatamonteiro@gmail.com.

Verônica Lima de Oliveira

Graduanda de psicologia do Centro universitário Augusto Motta. E-mail: veronica.l.o@ hotmail.com.

\section{Rachel Shimba Carneiro}

Professora do Curso de Psicologia do Centro Universitário Augusto Motta. Doutora em Psicologia Social pela Universidade do Estado do Rio de Janeiro (UERJ).E-mail: rachelshimba@souunisuam.com.br.

Resumo: Considerando a importância das habilidades sociais e da autoeficácia para os universitários, o presente estudo teve como objetivo verificar a relação entre as habilidades sociais e a percepção de autoeficácia geral de 125 universitários de uma faculdade particular do Rio de Janeiro, em final de curso. Além disso, a pesquisa analisou a diferença de tais variáveis entre 46 estudantes de psicologia, 40 do curso de engenharia e 35 de enfermagem. Para avaliar as habilidades sociais, foi utilizado o Inventário de Habilidades Sociais (IHS) que compreende cinco fatores: Enfrentamento e autoafirmação com risco; Autoafirmação na expressão de sentimento positivo; Conversação e desenvoltura social; Autoexposição a desconhecidos e situações novas; Autocontrole da agressividade. Com base nos escores totais obtidos no IHS, foi verificado que $83(68 \%)$ estudantes apresentaram bons repertórios de habilidades sociais e 36 (30\%) obtiveram escores abaixo da média. Para verificar a percepção de autoeficácia geral, foi aplicada a Escala de Autoeficácia Geral Percebida. Em relação a esta escala, 28 $(23,6 \%)$ participantes apresentaram escores abaixo da média pesquisada. A partir do coeficiente de correlação de Spearman, foi encontrada uma correlação direta e significativa apenas entre o escore do fator autoexposição a desconhecidos e situações novas e o escore da autoeficácia $(\mathrm{p}=0,016)$. A partir deste estudo, será possível considerar algumas estratégias que venham proporcionar o desenvolvimento das habilidades sociais e da autoeficácia nas Instituições de Ensino Superior.

Palavras-chave: Habilidades sociais. Autoeficácia. Universitários.

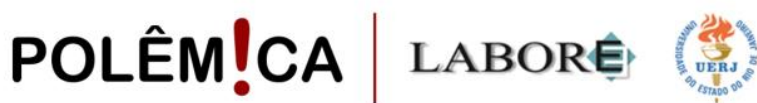

Polêmica - Revista Eletrônica da Uerj - Rua São Francisco Xavier, 524, $1^{\circ}$ andar bloco D, sl.1001 • Tels.: +55 21 2334-4088 / 4087 • http://www.e-publicacoes.uerj.br/index.php/polemica/index http://www.labore.uerj.br • laboreuerj@yahoo.com.br 


\title{
SOCIAL SKILLS AND SELF-EFFICACY IN UNDERGRADUATES
}

\begin{abstract}
Considering the importance of social skills and self-efficacy for undergraduates, this study aimed to verify the relationship between social skills and the perception of general self-efficacy in 125 undergraduate students at a private college in Rio de Janeiro. In addition, the research analyzed the difference of such variables among 46 psychology students, 40 engineering students and 35 nursing students. To evaluate social skills, the Social Skills Inventory (IHS) was used, which includes five factors: Confrontation and self-assertion with risk; Self-affirmation in the expression of positive feeling; Conversation and social entrepreneurship; Self-exposure to strangers and new situations; Self-control of aggressiveness. Based on the IHS scores, 83 (68\%) students had good social skills repertoires and $36(30 \%)$ had below-average scores. To verify the perception of general selfefficacy, the Perceived General Self-Efficacy Scale was applied. In relation to this scale, 28 (23.6\%) participants had scores below the mean searched. From Spearman's correlation coefficient, a significant direct correlation was found only between the self-exposed factor score and the new self-efficacy score $(p=0.016)$. From this study, it will be possible to consider some strategies that will provide the development of social skills and selfefficacy in Higher Education Institutions.
\end{abstract}

Keywords: Social skills. Self-efficacy. University students.

\section{Introdução}

Atualmente, o mercado de trabalho, cada vez mais globalizado e competitivo, demanda profissionais com alto rendimento técnico, porém, percebe-se que os conhecimentos acadêmicos não têm sido suficientes para suprir as necessidades do mercado. Silveira et al. (2016, p. 60) explicam:

Se a presença de um repertório habilidoso nas interações é importante para o convívio social, ainda mais acentuadas são essas exigências quando se trata de atuações nos complexos contextos de trabalho, uma vez que suas atividades colocam, necessariamente, os indivíduos em constantes interações com outras pessoas.

Para Del Prette e Del Prette (2017), o conceito de Habilidades Sociais se refere aos comportamentos sociais valorizados em determinada cultura, com alta probabilidade de resultados favoráveis para o indivíduo, pessoas próximas e comunidade, que podem colaborar para o desempenho socialmente competente, considerando os padrões da comunidade em que estiver inserido, favorecendo relações interpessoais funcionais, satisfatórias e produtivas entre pessoas em interação.

Del Prette e Del Prette (2001) refletem ainda sobre as relações sociais nas organizações: "Os novos paradigmas organizacionais que orientam a reestruturação produtiva têm priorizado processos de trabalho que remetem, diretamente, à natureza e à qualidade das relações interpessoais" (p. 57). É cada vez mais claro que a competência técnica é fundamental para o exercício das atividades profissionais, porém, muitas vezes as competências sociais não são devidamente valoradas. Em uma revisão da literatura, foi

\section{POLÊM!CA $\mid$ LABORE}

Polêmica - Revista Eletrônica da Uerj - Rua São Francisco Xavier, 524, $1^{\circ}$ andar bloco D, sl.1001 • Tels.: +55 21 2334-4088 / 4087 • http://www.e-publicacoes.uerj.br/index.php/polemica/index http://www.labore.uerj.br • laboreuerj@yahoo.com.br 
constatado que indivíduos com um repertório adequado de habilidades sociais podem ter mais sucesso em suas vidas, o que pode dirimir os efeitos negativos das vivências estressantes que venham a passar (BANDEIRA et al., 2006).

Neste contexto, é importante chamar atenção para a formação dos universitários, refletindo se as instituições estão preparando os alunos para os diversos desafios e necessidades de relacionamentos que o mercado exige. Soares, Poubel e Mello (2009) sustentam a importância de desenvolver habilidades sociais na formação dos universitários, pois funcionarão como facilitador no desempenho técnico e social do estudante. Considerando que as habilidades sociais não estão sendo abordadas de forma satisfatória, nos cursos universitários, Bandeira et al. (2006, p. 140) nos trazem a seguinte reflexão:

\footnotetext{
Esta tendência sugere implicitamente, pelo menos, duas explicações: que as habilidades necessárias para lidar com situações de interação social estão sendo consideradas como parte já existente no repertório dos alunos, portanto, sem necessidade de ser desenvolvida nos cursos ou, então, que a importância deste repertório de habilidades sociais tem sido subestimada ou considerada como relativamente pouco importante, comparativamente aos conhecimentos técnicos a serem ensinados no curso.
}

Del Prette e Del Prette (1998) apontam que estudos desenvolvidos com o objetivo de avaliar as habilidades sociais em universitários têm indicado que o nível de habilidade social se correlaciona de forma direta com outras variáveis como a atenciosidade, a compreensividade, a empatia e a agradabilidade, sendo essas características facilitadoras na inserção profissional. Além disso, os autores indicam que a competência acadêmica esperada dos universitários, para que obtenham bons resultados e aproveitamento cognitivo satisfatório, se relaciona profundamente com a competência social. A competência social remete para o conjunto de comportamentos demonstrados pelo indivíduo, em um contexto interpessoal, através da expressão de sentimentos, atitudes, desejos, opiniões e direitos de forma coerente com a situação, respeitando os comportamentos dos outros e que de forma geral soluciona os problemas imediatos, reduzindo assim a possibilidade de conflitos no futuro (CABALLO, 2003). A competência social mantém e melhora a qualidade na relação com oscolegas, professores e gestores, aumentando a autoestima e a autoeficácia (DEL PRETTE; DEL PRETTE, 1998).

A autoeficácia é um construto influente na motivação. De acordo com Bandura (1997,

\section{POLÊM!CA $\mid$ LABORE}

Polêmica - Revista Eletrônica da Uerj - Rua São Francisco Xavier, 524, $1^{\circ}$ andar bloco D, sl.1001 • Tels.: +55 21 2334-4088 / 4087 • http://www.e-publicacoes.uerj.br/index.php/polemica/index http://www.labore.uerj.br • laboreuerj@yahoo.com.br 
p. 2), "o nível de motivação, os estados afetivos e as ações das pessoas baseiam-se mais no que elas acreditam do que no que é objetivamente verdadeiro". O mesmo autor sustenta que o mecanismo de autoeficácia está centralizado na autopercepção de eficácia e que cada indivíduo é capaz de influenciar suas próprias ações, pensamentos e emoções (BANDURA, 1997).

O construto da autoeficácia corresponde a um dos pilares da Teoria Social Cognitiva (TSC). As crenças de autoeficácia constituem a base da motivação de um indivíduo e se relacionam com a autopercepção do mesmo acerca do seu potencial, sendo definida pelo julgamento que o indivíduo tem sobre suas capacidades em organizar cursos de ação para obter específicos tipos de desempenho. De acordo com os autores, os estudantes que apresentam uma crença de autoeficácia adequada têm uma boa percepção em relação à capacidade de executar as tarefas agendadas (BANDURA; AZZI, 2017).

De acordo com Pajares e Olaz (2008), desde que o conceito de autoeficácia foi introduzido, em 1977, por Albert Bandura, muitos pesquisadores se dedicaram a estudar o assunto. Na psicologia ela tem sido focada em estudos que correlacionam o tema com problemas clínicos, habilidades sociais, assertividade, tabagismo, entre outros. Nestes estudos, os pesquisadores estabeleceram que as crenças de autoeficácia influenciam fortemente as realizações em diversos campos e estão altamente correlacionadas com as mudanças de comportamento, mediando o efeito de habilidades, capacidades mentais e experiências prévias, sendo um excelente preditor do comportamento (PAJARES; OLAZ, 2008). As crenças de autoeficácia são "julgamentos cognitivos de competência, referenciados por objetivos relativamente específicos ao contexto e orientados para o futuro" (PAJARES; OLAZ, 2008, p. 112).

Segundo Bandura (1997), a crença de autoeficácia será formada a partir das informações recebidas de quatro principais fontes, que são elas: (1) Experiência direta, que se baseia em resultados das próprias experiências; (2) Experiência vicária, que se refere à capacidade do ser humano aprender com as experiências vividas por outras pessoas; (3) Persuasão social, quando o ambiente social promove a percepção de que a pessoa possui as capacidades para resolver diversas situações; e (4) Estado físico e emocional, pois dependendo das circunstâncias, a ansiedade e o estresse, bem como o sono e o cansaço

\section{POLÊM!CA $\mid$ LABORE}

Polêmica - Revista Eletrônica da Uerj - Rua São Francisco Xavier, 524, $1^{\circ}$ andar bloco D, sl.1001 • Tels.: +55 21 2334-4088 / 4087 • http://www.e-publicacoes.uerj.br/index.php/polemica/index http://www.labore.uerj.br • laboreuerj@yahoo.com.br 
físico influenciam a percepção da própria capacidade e da competência frente à resolução de determinada situação.

A partir desse conceito é possível ajudar a explicar diversos fenômenos, como as mudanças no comportamento de enfrentamento; os níveis de reações fisiológicas do estresse; a autorregulação do comportamento; a resignação e o desânimo diante de experiências ligadas ao fracasso; os efeitos de descontrole; a ilusão da ineficácia; a luta por realizações; o crescimento do interesse intrínseco; e as buscas profissionais (BANDURA, 1997).

Os estudos de Pajares e Olaz (2008) relatam que estudantes confiantes em suas habilidades sociais preveem interações sociais bem-sucedidas. Por outro lado, os estudantes que duvidam de suas habilidades sociais, acreditam que serão rejeitados ou ridicularizados mesmo antes de estabelecerem contato social (PAJARES; OLAZ, 2008). Estima-se sucesso social e mais opções de carreira para os estudantes que acreditam em suas potencialidades, e isolamento social ou poucas possibilidades acadêmicas para os que fazem uma avaliação negativa de suas competências (PAJARES; OLAZ, 2008).

Com base nos estudos consultados até o momento, pode-se perceber que um repertório adequado de habilidades sociais traz efeitos significativos na vida das pessoas, contribuindo para sua inclusão e aceitação em diversos ambientes e grupos, o que pode lhes proporcionar maior interação social, qualidade de vida, redução de sintomas ansiosos e sucesso tanto na vida pessoal quanto profissional. O presente estudo pretende verificar se as habilidades sociais estão relacionadas de alguma forma com uma maior percepção de autoeficácia nos universitários.

\section{Método}

\section{$\underline{\text { Participantes }}$}

A amostra compreendeu um grupo de 121 estudantes, mesclando estudantes dos cursos de Psicologia (46 estudantes), Enfermagem (35 estudantes) e Engenharia Civil (40 estudantes), que estão cursando o $8^{\circ}, 9^{\circ}$ ou $10^{\circ}$ período de seus respectivos cursos.

\section{POLÊM!CA $\mid$ LABORE}

Polêmica - Revista Eletrônica da Uerj - Rua São Francisco Xavier, 524, $1^{\circ}$ andar bloco D, sl.1001 • Tels.: +55 21 2334-4088 / 4087 • http://www.e-publicacoes.uerj.br/index.php/polemica/index http://www.labore.uerj.br • laboreuerj@yahoo.com.br 


\section{Material}

A participação dos estudantes nesta pesquisa incluiu o preenchimento dos seguintes instrumentos:

- Termo de Consentimento Livre e Esclarecido: Documento em que constam os esclarecimentos necessários para que os participantes manifestem explicitamente seu consentimento de participação. Inclui: objetivo, procedimentos, garantia de sigilo e benefícios da pesquisa.

- Inventário de Habilidades Sociais (IHS) (DEL PRETTE; DEL PRETE, 2001): Instrumento utilizado para avaliação das Habilidades Sociais dos universitários. Seu objetivo é avaliar o desempenho social em diferentes situações. O IHS compreende 38 itens que descrevem situações sociais em diversos âmbitos como trabalho, lazer e família; em situações propostas como falar em público, manter uma conversa, recusar um pedido, elogiar e receber elogio. Del Prette e Del Prette (2001) estruturam o inventário em cinco fatores: (1) Enfrentamento e Autoafirmação com risco - indica a capacidade para lidar com situações interpessoais que demandam afirmação e defesa de direitos e autoestima, com risco potencial de reação indesejável por parte do interlocutor; (2) Autoafirmação na expressão de sentimento positivo - indica habilidades para lidar com expressão de afeto positivo e de afirmação da autoestima, que não envolve risco interpessoal ou apenas um risco mínimo indesejável; (3) Conversação e Desenvoltura Social - capacidade de lidar com situações neutras de aproximação (em termos de afeto positivo e negativo), com risco mínimo de reação indesejável, demandando principalmente "traquejo social" na conversação; (4) Autoexposição a desconhecidos e situações novas - indica capacidade de abordar pessoas desconhecidas, semelhante ao fator anterior, porém com maior risco de reação indesejável do outro; (5) Autocontrole da agressividade - capacidade de reagir a estimulações negativas do interlocutor com razoável controle da raiva e da agressividade.

- Escala de Autoeficácia Geral Percebida: Trata-se de uma escala do tipo likert, composta por dez itens, com respostas que variam de 1 a 4 . O objetivo da escala é avaliar de que forma os estudantes percebem sua capacidade para lidar com as mais adversas situações como enfrentar desafios, alcance de metas, sua posição diante de

\section{POLÊM!CA $\mid$ LABORE}

Polêmica - Revista Eletrônica da Uerj - Rua São Francisco Xavier, 524, $1^{\circ}$ andar bloco D, sl.1001 • Tels.: +55 21 2334-4088 / 4087 • http://www.e-publicacoes.uerj.br/index.php/polemica/index http://www.labore.uerj.br • laboreuerj@yahoo.com.br 
imprevistos e atribuição interna estável de sucesso. Entende-se que quanto maior a pontuação atribuída ao item, maior a percepção de autoeficácia do entrevistado. A escala utilizada foi revalidada como a versão brasileira final por Gomes-Valério (2016).

\section{Procedimento}

Após a aprovação do projeto pelo Comitê de Ética e Pesquisa, foi realizada a divulgação do estudo dentro de uma universidade da zona norte do Rio de Janeiro, a fim de recrutar, de forma aleatória, os estudantes que estavam cursando os últimos semestres de seus cursos. Os universitários que aceitaram participar da pesquisa foram orientados a assinar o Termo de Consentimento Livre e Esclarecido, em duas vias. Em seguida, foi realizada a aplicação do Inventário de Habilidades Sociais e da Escala de Autoeficácia Percebida. Foram descartados quatro testes por preenchimento inválido.

\section{$\underline{\text { Análise de dados }}$}

Primeiramente, foi realizada a análise descritiva de caráter exploratório, a fim de avaliar os casos omissos e possíveis erros de digitação. Na segunda etapa, foi realizada a análise quantitativa, a fim de apresentar a correlação entre as variáveis: habilidades sociais e a percepção de autoeficácia. Para a análise de dados, foi criado um banco de dados no programa SPSS 22 (IBM Corporation, EUA), com as informações obtidas no Inventário de Habilidades Sociais e na Escala de Autoeficácia Geral Percebida. O escore total das variáveis do estudo foi descrito como média \pm DP. O coeficiente de correlação de Spearman foi utilizado para avaliar a associação entre os escores totais dos instrumentos utilizados. O nível de significância adotado foi de $p<0,05$.

\section{Resultados}

$\underline{\text { Avaliação das habilidades sociais a partir do inventário de habilidades sociais }}$

Para verificar a diferença das habilidades sociais entre estudantes de enfermagem, psicologia e engenharia civil, foram computadas as médias referentes aos cinco fatores do IHS: $\left(1 .^{\circ}\right)$ Enfrentamento e autoafirmação com risco; $\left(2 .^{\circ}\right)$ Autoafirmação na expressão de

\section{POLÊM!CA $\mid$ LABORE}

Polêmica - Revista Eletrônica da Uerj - Rua São Francisco Xavier, 524, $1^{\circ}$ andar bloco D, sl.1001 • Tels.: +55 21 2334-4088 / 4087 • http://www.e-publicacoes.uerj.br/index.php/polemica/index http://www.labore.uerj.br・ laboreuerj@yahoo.com.br 
sentimentos positivos; $\left(3^{\circ}\right)$ Conversação e desenvoltura social; $\left(4 .^{\circ}\right)$ Autoexposição a desconhecidos e situações novas e o (5..$^{\circ}$ Autocontrole da agressividade.

$\mathrm{Na}$ figura 1, pode-se observar as médias obtidas pelos grupos em cada fator e em quais habilidades os estudantes se destacam, ou possuem maior dificuldade.

Figura - 1: Médias dos fatores do IHS nos grupos

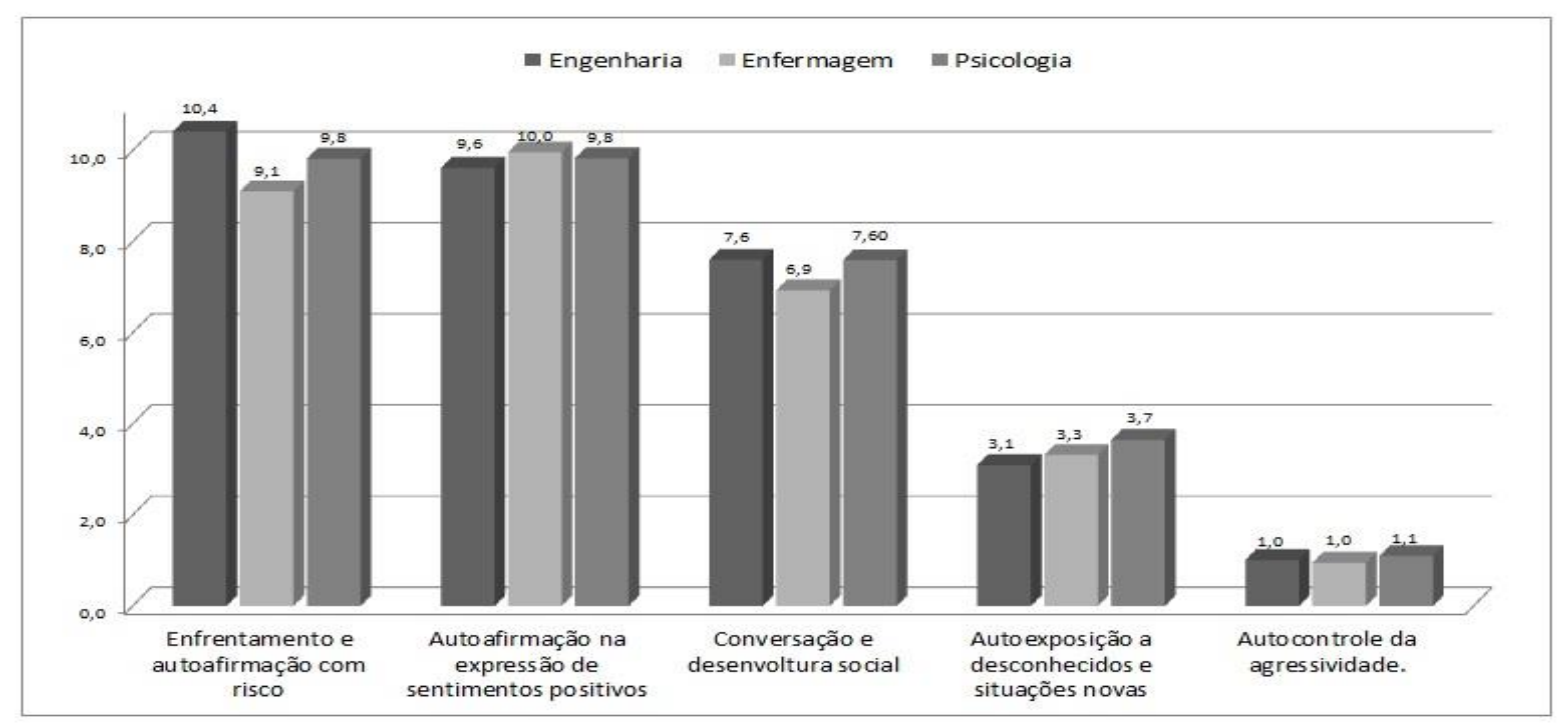

Fonte: Os autores, 2019.

A partir das médias apresentadas na figura 1, não foram encontradas diferenças significativas entre os grupos pesquisados nos fatores do IHS.

Em relação aos escores totais obtidos no IHS, foi verificado que 83 (68\%) estudantes apresentaram bons repertórios de habilidades sociais e 36 (30\%) obtiveram escores abaixo da média, como pode ser observado no gráfico a seguir.

\section{POLÊM!CA $\mid$ LABORE}

Polêmica - Revista Eletrônica da Uerj - Rua São Francisco Xavier, 524, $1^{\circ}$ andar bloco D, sl.1001 • Tels.: +55 21 2334-4088 / 4087 • http://www.e-publicacoes.uerj.br/index.php/polemica/index http://www.labore.uerj.br • laboreuerj@yahoo.com.br 
Figura - 2: Repertório de Habilidades Sociais dos estudantes
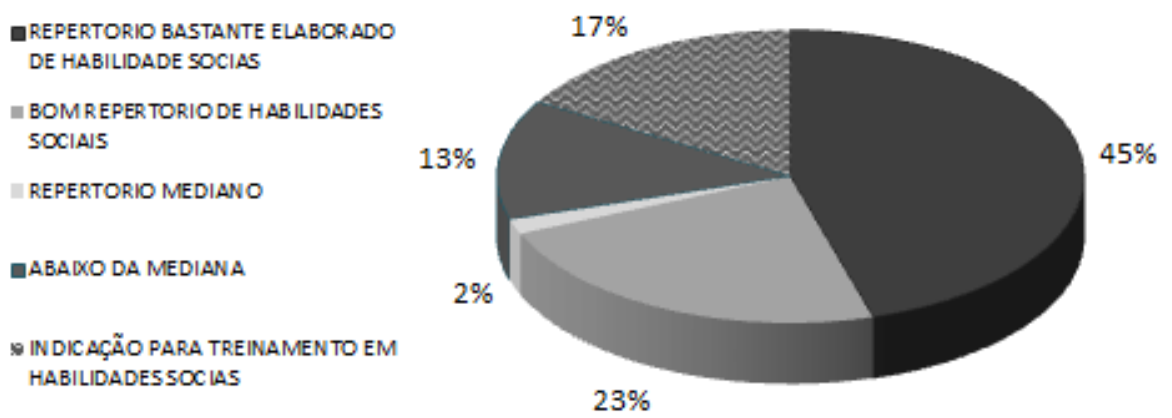

Fonte: Os autores, 2019.

$\underline{\text { Avaliação da autoeficácia a partir da escala de Autoeficácia Geral Percebida }}$

Com base na Escala de Autoeficácia Geral Percebida, foram identificadas diferenças significativas entre os três grupos pesquisados: (1) Grupo dos estudantes de Psicologia $(30,63 \pm 4,51)$; (2) Grupo dos estudantes de Engenharia $(33,30 \pm 3,19)$ e (3) Grupo dos estudantes de Enfermagem $(32,77 \pm 4,80, \mathrm{p}=0,010)$. O grupo dos estudantes de Psicologia obteve escore abaixo da média e o grupo dos estudantes de Engenharia Civil e Enfermagem obtiveram resultados acima da média.

A análise do coeficiente de correlação de Spearman constatou uma correlação direta significativa apenas entre o escore do fator Autoexposição a desconhecidos e situações novas e o escore da Autoeficácia $(\mathrm{p}=0,016)$.

É interessante notar que os estudantes do gênero masculino apresentaram níveis significativamente maiores de autoeficácia quando comparados com as do sexo feminino, conforme apresentado na figura 3.

\section{POLÊM!CA | LABORÊ}

Polêmica - Revista Eletrônica da Uerj - Rua São Francisco Xavier, 524, $1^{\circ}$ andar bloco D, sl.1001 • Tels.: +55 21 2334-4088 / 4087 • http://www.e-publicacoes.uerj.br/index.php/polemica/index http://www.labore.uerj.br • laboreuerj@yahoo.com.br 
Figura - 3: Comparação da autoeficácia entre os sexos

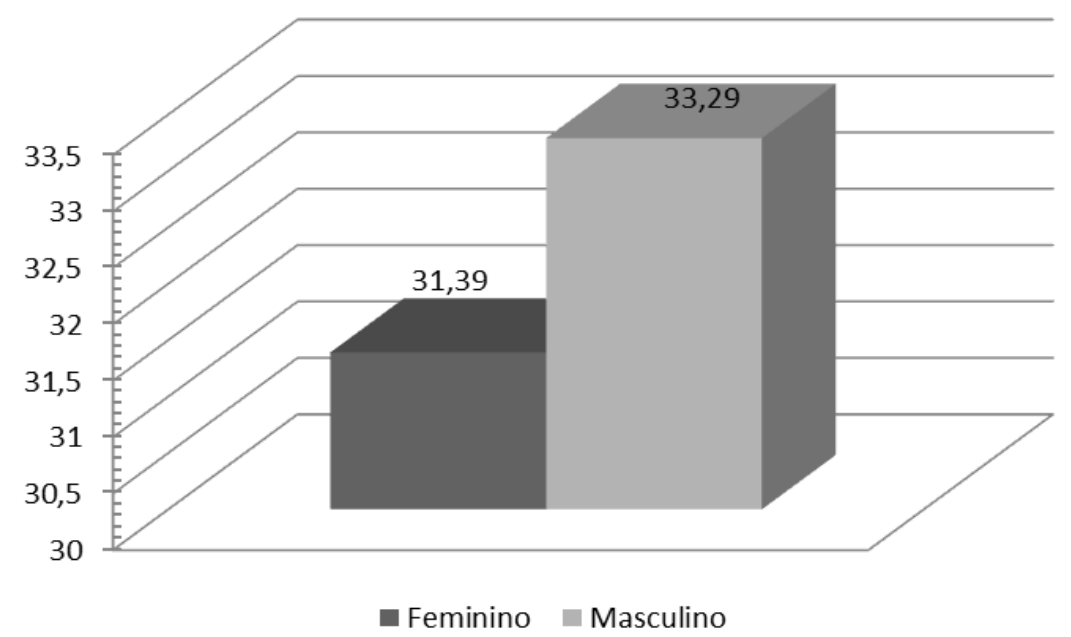

Fonte: Os autores, 2019.

\section{Discussão dos resultados}

$\mathrm{Na}$ análise dos escores totais obtidos a partir do Inventário de Habilidades Sociais (DEL PRETTE; DEL PRETTE, 2001), foi verificado que 68\% dos estudantes apresentaram bons repertórios de habilidades sociais e 30\% obtiveram escores abaixo da média, indicando que ao menos $30 \%$ dos participantes desta pesquisa se beneficiariam com algum tipo de auxílio para o desenvolvimento das habilidades sociais com o objetivo de prevenir possíveis problemas na vida acadêmica e profissional.

Além disso, foi observado que a maioria dos participantes apresentou um maior repertório de habilidades sociais em situações que envolvem a autoafirmação na expressão de sentimentos positivos. São exemplos de situações que representam essas habilidades: elogiar familiares e outras pessoas; expressar sentimento positivo; agradecer elogios ou participar de conversas triviais. Entretanto, foi possível perceber que os estudantes apresentaram um menor repertório de habilidades sociais nas situações de autocontrole da agressividade. Cabe destacar que nos três grupos investigados, os homens obtiveram escores abaixo da média para essa habilidade que envolve lidar com críticas, chacotas ou brincadeiras ofensivas. É importante considerar que esta capacidade de reagir a estimulações negativas do interlocutor, com razoável controle da raiva e da agressividade, não significa deixar de expressar desagrado ou ira, mas fazê-lo de forma socialmente competente e assertiva.

Outro fator observado é que os estudantes do curso de Psicologia apresentaram um repertório de habilidades socias discretamente mais elaborado do que os estudantes dos outros

\section{POLÊM!CA $\mid$ LABORE}

Polêmica - Revista Eletrônica da Uerj - Rua São Francisco Xavier, 524, $1^{\circ}$ andar bloco D, sl.1001 • Tels.: +55 21 2334-4088 / 4087 • http://www.e-publicacoes.uerj.br/index.php/polemica/index http://www.labore.uerj.br • laboreuerj@yahoo.com.br 
dois cursos. Entretanto, os estudantes de Engenharia Civil destacaram-se no fator Enfrentamento e Autoafirmação com risco. Este fator indica a capacidade para lidar com situações interpessoais que demandam afirmação e defesa de direitos com risco potencial de reação indesejável por parte do interlocutor (possibilidade de rejeição, réplica ou de oposição).

Já os resultados referentes à autoeficácia indicaram uma diferença significativa entre os grupos. O grupo dos estudantes de Psicologia apresentaram resultados abaixo da média, os estudantes dos cursos de Enfermagem, discretamente acima da média, e os estudantes de Engenharia Civil obtiveram escores acima da média.

Ao perceber que os resultados referentes à autoeficácia do grupo de universitários do curso de Engenharia eram significativamente superior aos demais cursos e levando em consideração que os estudantes deste curso são, em sua maioria, do sexo masculino, foram analisados os níveis da autoeficácia percebida entre homens e mulheres dos três grupos. Verificou-se que estudantes do gênero masculino apresentaram níveis consideravelmente maiores de autoeficácia, quando comparados às estudantes do sexo feminino. Estudos de Pelissoni (2007) contribui com a seguinte reflexão:

\begin{abstract}
Pesquisas realizadas em diferentes domínios acadêmicos mostram que as mulheres se diferem dos homens em relação às suas crenças de auto-eficácia (BEYER, 1994; PAJARES, 1996, 2002; PHILIPS \& ZIMMERMAN, 1990). Pajares (2002) indica que esta diferença de crença, em relação ao domínio da Matemática, pode ser atribuída a diferentes fatores. Mas o que parece ser significativo refere-se ao desenvolvimento característico da adolescência, os homens nesta fase da vida são mais confiantes enquanto as mulheres são modestas perante a avaliação de suas capacidades em relação à Matemática. Bussey e Bandura (1999) contribuem para o entendimento da proposição anterior quando demonstram que alguns comportamentos explicam o desenvolvimento de algumas características ligadas ao gênero. Ou seja, parte dos comportamentos ligados ao gênero são modelados e mantidos por influências sociais e culturais. Um exemplo, em nossa cultura refere-se às profissões. É muito comum que as pessoas tendam a não escolher algumas carreiras por considerar que não têm habilidades para esta atuação, pois a habilidade está socialmente relacionada a estereótipos de gênero. Um exemplo seria o caso da profissão de engenharia que está associada a uma grande habilidade em Matemática, que por sua vez é tipicamente associada ao gênero masculino. (PELISSONI, 2007, p. 46).
\end{abstract}

\title{
Considerações finais
}

Com os resultados obtidos neste estudo e considerando a necessidade de um satisfatório repertório de habilidades sociais para o sucesso acadêmico e profissional, pretende-se reforçar a relevância de que os cursos de graduação adotem programas e

\section{POLÊM!CA $\mid$ LABORE}

Polêmica - Revista Eletrônica da Uerj - Rua São Francisco Xavier, 524, $1^{\circ}$ andar bloco D, sl.1001 • Tels.: +55 21 2334-4088 / 4087 • http://www.e-publicacoes.uerj.br/index.php/polemica/index http://www.labore.uerj.br • laboreuerj@yahoo.com.br 
estratégias voltadas para o desenvolvimento das habilidades sociais, sobretudo, os cursos cujo sucesso profissional depende da qualidade das relações que o estagiário e futuro profissional estabelece com clientes, gestores e outros colaboradores. Corroborando, desta forma, as determinações da LDB 9.394/96 (BRASIL, 1996) que sugerem o desenvolvimento das habilidades e competências do estudante.

É importante ressaltar que o desenvolvimento de habilidades sociais não é uma ferramenta útil apenas para pessoas que apresentam dificuldades nas relações sociais, mas pode ser benéfico para quem deseja aumentar as suas habilidades sociais, em função de demandas pessoais ou questões profissionais.

Não foi encontrada correlação entre o escore total do Inventário de Habilidades Sociais e o escore da Escala de Autoeficácia Geral e Percebida. Entretanto, foi identificada uma correlação diretamente significativa entre a autoexposição a desconhecidos e situações novas e o constructo da autoeficácia. Isso mostra que quanto maior a percepção de autoeficácia, maior será a facilidade de se expor, se arriscar perante novos desafios e situações que envolvam desconhecidos, mesmo que esta exposição envolva o risco de reação indesejável do outro.

De acordo com os resultados obtidos, é possível perceber que a preocupação com o desempenho acadêmico e aprendizagem das habilidades técnicas não deve deixar de lado o foco na promoção das habilidades sociais dos alunos. A implantação de programas e atividades para o desenvolvimento de habilidades sociais em universitários poderá proporcionar grande benefício aos estudantes. A partir deste estudo, pode-se verificar a importância da implantação de grupos para o desenvolvimento das habilidades sociais, buscando aumentar os comportamentos socialmente adequados, diminuir as deficiências em habilidades sociais e fortalecer a percepção de autoeficácia destes universitários.

\section{Referências}

BANDEIRA, M. et al. Habilidades interpessoais na atuação do psicólogo. Interação em Psicologia, Curitiba, v. 10, n. 1, p. 139-149, jan./jun. 2006.

BANDURA, A. Self-efficacy: The exercise of control. New York: Freeman, 1997.

BANDURA, A; AZZI, R (Org). Teoria Social Cognitiva: diversos Enfoques. Campinas, SP: Mercado de Letras, 2017.

\section{POLÊM!CA $\mid$ LABORE}

Polêmica - Revista Eletrônica da Uerj - Rua São Francisco Xavier, 524, $1^{\circ}$ andar bloco D, sl.1001 • Tels.: +55 21 2334-4088 / 4087 • http://www.e-publicacoes.uerj.br/index.php/polemica/index http://www.labore.uerj.br • laboreuerj@yahoo.com.br 
BRASIL. Ministério de Educação e Cultura. Lei nº 9.394/96, de 20 de dezembro de 1996. Estabelece as diretrizes e bases da Educação Nacional. Diário Oficial da União, Brasília, DF, 23 dez. 1996.

CABALLO, V. E. Manual de avaliação e treinamento das habilidades sociais. São Paulo: Santos, 2003.

DEL PRETTE, A.; DEL PRETTE, Z. A. P. Psicologia das habilidades sociais: terapia e educação. Petrópolis: Vozes, 1998.

DEL PRETTE, Z. A. P.; DEL PRETTE, A. Inventário de Habilidades Sociais (IHS-Del-Prette): Manual de aplicação, apuração e interpretação. São Paulo: Casa do Psicólogo, 2001.

DEL PRETTE, Z. A. P.; DEL PRETTE, A. Competência social e habilidades sociais: Manual teórico-prático. Petrópolis: Editora Vozes, 2017.

FURTADO, E.; FALCONE, E.; CLARK, C. Avaliação do estresse e das habilidades sociais na experiência acadêmica de estudantes de medicina de uma universidade do Rio de Janeiro. Interação em Psicologia, Rio de Janeiro, v. 7, n. 3, p. 43-51, jul./dez. 2003.

GOMES-VALÉRIO, J. O. Apresentação da versão brasileira definitiva da escala de autoeficácia geral percebida. In: CONGRESSO DE PSICOLOGIA DA ZONA DA MATA E VERTENTES, 9, 2016, Juiz de Fora. Anais... Juiz de Fora: AJEPSI, 2016. p. 1-3.

PACHECO, P.; RANGÉ B. Desenvolvimento de habilidades sociais em graduandos de Psicologia. In: BANDEIRA, M.; DEL PRETTE, Z. A. P.; DEL PRETTE, A. (Org.). Estudos sobre habilidades sociais e relacionamento interpessoal. São Paulo: Casa do Psicólogo, 2006. p. 199-216.

PAJARES, F.; OLAZ, F. Teoria social cognitiva e autoeficácia: uma visão geral. In: BANDURA, A.; AZZI, R. G.; POLYDORO, S. (Org.). Teoria Social Cognitiva, Conceitos Básicos. Porto Alegre: Artmed, 2008.

PELISSONI, A. M. Auto-eficácia na transição para trabalho e comportamentos de exploração de carreira em licenciandos. Dissertação (Mestrado em Educação) - Universidade Estadual de Campinas, Faculdade de Educação, Campinas, SP, 2007.

SILVEIRA, A. et al. Identificação de Habilidades Sociais Profissionais em líderes que atuam em unidades acadêmicas e administrativa de uma IES Pública. In: GOULART J. E. et al. Psicologia organizacional e do trabalho e orientação profissional na formação do psicólogo. Araraquara: Letraria, 2016. p. 57-71.

SOARES, A. B.; POUBEL, L. N.; MELLO, T. V. S. Habilidades sociais e adaptação acadêmica: um estudo comparativo em instituições de ensino público e privado. Aletheia, Canoas, n. 29, p. 27-42, jun. 2009.

TEIXEIRA, M. A. P.; GOMES, W. B. Decisão de carreira entre estudantes em fim de curso universitário. Psicologia: Teoria e Pesquisa, v. 21, n. 3, p. 327-334, 2005.

Recebido em: 30/03/2019.

Aceito em: 30/05/2019.

\section{POLÊM!CA $\mid$ LABORE}

Polêmica - Revista Eletrônica da Uerj - Rua São Francisco Xavier, 524, $1^{\circ}$ andar bloco D, sl.1001 • Tels.: +55 21 2334-4088 / 4087 • http://www.e-publicacoes.uerj.br/index.php/polemica/index http://www.labore.uerj.br・ laboreuerj@yahoo.com.br 